\title{
Técnica bilaminar en el tratamiento de una recesión gingival: presentación de caso
}

\author{
Bilaminar technique in the treatment \\ of gingival recession: Case study
}
Rosario Cruz-Morales $^{1} \bowtie$, Dunia Caballero López ${ }^{2}$, Ileana García-Rodríguez ${ }^{2}$
${ }^{1}$ Universidad de Ciencias Médicas de la Habana, Facultad de Ciencias Médicas de Matanzas, Cuba.
${ }^{2}$ Universidad de Ciencias Médicas de Matanzas "Dr. Juan Guiteras Gener", Matanzas, Cuba.

Universidad de Ciencias Médicas “Juan Guiteras Gener”, Matanzas, Cuba. Dirección: Calle 140 Edif. 18 apto. 7, Rpto. Reynold García. Teléfono: 45265711. Correo electrónico: rosarioc.mtz@infomed.sld.cu

Recibido: 17 de enero del 2017 Aprobado: 26 de marzo del $2017 \quad$ Disponible en línea: 1 de enero del 2018

Cómo citar este artículo: Cruz Morales R, Caballero López D, García Rodríguez I. Técnica bilaminar en el tratamiento de una recesión gingival. Presentación de caso. Rev Nac Odontol. 2018;14(27), enero 2018. doi: https://doi.org/10.16925/ od.v14i27.2343

\section{Resumen}

Introducción: las recesiones gingivales ocasionan problemas estéticos y aparecen por el desplazamiento del margen gingival hacia apical del límite amelocementario. Dejan expuestas las superficies radiculares, de manera que aumentan la susceptibilidad a caries radicular, hiperestesia dentinal y abrasiones cervicales. Son multifactoriales; Miller las clasificó según su extensión con el fin de determinar el grado de cobertura radicular que podría esperarse después de realizar un tratamiento quirúrgico.

Propósito: describir un caso de recesión gingival clase ॥ de Miller localizada en el 44, en el que se realizó un injerto de tejido conectivo subepitelial cubierto por un colgajo desplazado coronalmente.

Materiales y método: paciente femenina con antecedentes de salud que acudió al servicio de periodoncia preocupada por "cambio de posición de la encía en un diente". Se diagnosticó recesión gingival clase ॥ de Miller localizada en el 44. Se realizó técnica bilaminar de injerto de tejido conectivo subepitelial combinado con colgajo de espesor parcial desplazado coronalmente.

Resultados: a los siete días evolucionó la paciente y se retiró sutura de zona donante; mostró buena cicatrización del área, de modo que se citó a la semana para retirar cemento quirúrgico y sutura de la zona injertada, y se observaron discretos signos de inflamación y cobertura radicular completa del 44. El examen al mes, a los tres y a los seis meses, evidenció: tejido gingival libre de inflamación, recesión gingival del 44 por completo cubierta, ganancia de encía insertada y armonía de color entre sitio injertado y área adyacente.

Conclusiones: la técnica aplicada mostró resultados favorables respecto a cobertura radicular, aumento de la cantidad de encía queratinizada y buen aspecto estético.

Palabras clave: recesión gingival, injerto de tejido conectivo subepitelial, técnica bilaminar. 


\title{
Bilaminar technique in the treatment of gingival recession: Case study
}

\begin{abstract}
Introduction: Gingival recessions cause aesthetic problems and appear due to the displacement of the gingival margin towards the apical wall of the amelocementary limit. They expose the root surfaces, and therefore increase the possibility of root caries, dentinal hyperesthesia and cervical abrasions. They are multifactorial, Miller classified them according to their extension in order to determine the degree of root coverage that could be expected after performing surgical treatment.
\end{abstract}

Purpose: To describe a case of Miller class ॥ gingival recession located in tooth 44. In this patient, a subepithelial connective tissue graft, covered with a coronally positioned flap was carried out.

Materials and method: A female patient with medical history who attended the periodontics service concerned about the "changing position of a tooth's gum". She was diagnosed with Miller class $\|$ gingival recession located in tooth 44. Bilaminar technique of subepithelial connective tissue graft, combined with coronally positioned flap of partial thickness was performed.

Results: After seven days the patient evolved and the suture was removed from the donor area where she showed a good healing process. The patient was therefore told to come again the following week to remove surgical cement and suture from the grafted area; discrete signs of inflammation and complete radicular coverage of 44 were observed. The subsequent appointments after a month, three and six months showed gingival tissue with no inflammation; the gingival recession of tooth 44 was completely covered, there was gain of inserted gum and color harmony between the grafted and adjacent areas.

Conclusions: The applied technique proved to have favorable results regarding root coverage, increase in the amount of keratinized gum and appropriate aesthetic appearance.

Keywords: gingival recession, subepithelial connective tissue graft, bilaminar technique.

\section{Técnica bilaminar no tratamento de uma recessão gengival: apresentação do caso}

\section{Resumo}

Introdução: as recessões gengivais causam problemas estéticos e aparecem devido ao deslocamento da margem gengival em direção apical do limite amelocementário. Elas deixam expostas as superfícies das raízes, de modo que aumentam a suscetibilidade à cárie radicular, hiperestesia dentinária e abrasões cervicais. Elas são multifatoriais; Miller as classificou de acordo com sua extensão, a fim de determinar o grau de cobertura radicular que poderia ser esperado após a realização de um tratamento cirúrgico.

Objetivo: descrever um caso de recessão gengival de classe II de Miller no dente 44, no qual foi realizado um enxerto de tecido conjuntivo subepitelial recoberto por um retalho de reposicionamento coronal.

Materiais e método: paciente do sexo feminino com histórico de saúde que procurou o serviço odontológico preocupada por "a mudança de posição da gengiva em um dente". Diagnosticou-se uma recessão gengival classe ॥ de Miller no dente 44. Realizou-se uma técnica bilaminar de enxerto de tecido conjuntivo subepitelial, combinado com retalho de espessura parcial reposicionado coronariamente.

Resultados: após sete dias, a paciente evoluiu e a sutura foi removida da área dadora. Ela teve boa cicatrização, de modo que uma semana depois foi citada para remover o cimento cirúrgico e a sutura da área enxertada. Observaram-se sinais discretos de inflamação e cobertura radicular completa do dente 44. Os exames após um, três e seis meses, mostraram: tecido gengival livre de inflamação, recessão gengival do 44 completamente coberta, ganho de gengiva inserida e harmonia de cores entre 0 sítio enxertado e a área adjacente.

Conclusões: a técnica aplicada mostrou resultados favoráveis quanto à cobertura radicular, aumento da quantidade de gengiva queratinizada e boa aparência estética.

Palavras-chave: recessão gengival, enxerto de tecido conjuntivo subepitelial, técnica bilaminar. 


\section{Introducción}

Uno de los motivos en la consulta clínica diaria son las recesiones gingivales (RG), definidas por Guirnald y Caffesse [1] como el desnudo parcial de la superficie radicular, debido a la migración apical del margen gingival en relación con la línea amelocementaria. Son multifactoriales, su frecuencia aumenta con la edad y su incidencia varía desde el $8 \%$ en los niños hasta el $100 \%$ luego de los 50 años $[2,3]$.

Las recesiones implican consecuencias negativas para quien las presentan, ya que dejan expuestas las superficies radiculares y las hacen más susceptibles a caries, hiperestesia dentinal y abrasiones cervicales, lo cual puede ocasionar también problemas estéticos. Cuando a estas se les suma la presencia de inflamación gingival y poca o nula encía insertada, existe entonces un problema mucogingival que puede comprometer el pronóstico del diente afectado $[2,4,5]$.

El tratamiento de las recesiones está indicado si se constata que son progresivas, si hay signos de inflamación gingival, si dificultan el control de la biopelícula, o bien si el paciente desea mejorar su aspecto estético $[5,6]$.

En su tratamiento quirúrgico se usan técnicas de cirugía plástica periodontal que persiguen, como principal objetivo, la cobertura radicular completa (CRC), con una apariencia adecuada respecto a los tejidos adyacentes. Dicho tratamiento se ha convertido en un aspecto importante para el periodoncista, quien necesita ser orientado en un proceso de toma de decisiones basado en evidencias a fin de estar en capacidad de planear el abordaje terapéutico, predecir el resultado y, por último, alcanzarlo [7].

Desde 1985 Miller [8] propuso una clasificación para determinar la probabilidad de cobertura radicular basándose en la extensión de las recesiones gingivales, así como en la presencia de tejidos interproximales. Según esta clasificación, el clínico puede anticipar el grado de cobertura radicular al obtener la cobertura completa en las clases I y II, en las que existe recesión de los tejidos marginales sin pérdida de inserción periodontal en el área interdental; una cobertura parcial en la clase III, en la que los tejidos marginales están retraídos hasta más allá de la unión mucogingival con pérdida de la inserción periodontal en la zona interdental o mala posición dentaria; y nula en la clase IV, en la que los tejidos marginales se extienden o van más allá de la unión mucogingival con avanzada pérdida de hueso o tejido blando en el área interdental o severa malposición dentaria.

El especialista no solo debe basarse en la clasificación de Miller para predecir la CRC. Existen también otros factores a considerar, entre los cuales se encuentra la anchura y la longitud de la recesión, factores anatómicos como la profundidad del vestíbulo, la convexidad radicular, la presencia de abrasiones radiculares (lesiones cervicales no cariosas), la dimensión de las papilas, el desequilibrio acentuado entre el plano óseo y dental, la proporción entre el área vascular/vascular, la existencia de mal posición dentaria severa (lo cual requiere tratamiento ortodóntico previo), hábitos de higiene oral inapropiados - que deben corregirse antes de la intervención-y el tabaquismo $[9,10]$.

Se requiere, además, del análisis personalizado de cada caso, la ejecución precisa de las técnicas quirúrgicas y la combinación con el injerto o biomaterial adecuado para lograr la cobertura [7].

En la literatura $[5,6,7-9,11-13]$ se describen diferentes procedimientos de cobertura radicular, entre los cuales se encuentran: colgajos posicionados lateral y coronalmente, injertos gingivales libres, técnicas de doble papila, colgajos semilunares y técnicas bilaminares que usan injertos de tejido conectivo subepitelial, regeneración tisular guiada, aplicación de proteínas del esmalte y matriz dérmica acelular.

La evidencia indica que entre las diversas técnicas descritas, las bilaminares pueden ser las de elección. Básicamente, las que utilizan un injerto de tejido conectivo (ITC) en combinación con un colgajo de avance coronal. Este es uno de los procedimientos quirúrgicos más usados y obtiene los mejores resultados a corto y largo plazo en términos de cobertura de la raíz y de aumento del tejido queratinizado, y tiene un porcentaje de éxito que va del $92 \%$ al $97 \%[5,6,11]$.

Lo introdujeron en 1985 Burton Langer y Laureen Langer [14], y consiste en la realización de un colgajo de espesor parcial en la zona de la recesión con dos descargas verticales en ambos lados del defecto, raspado y alisado de la raíz, colocación del injerto de tejido conectivo subepitelial, reposición del colgajo y sutura.

Está indicado cuando existe un inadecuado sitio donador para desplazar un colgajo horizontal, en recesión gingival ancha aislada, en múltiples 
raíces expuestas en combinación con una mínima encía insertada y en recesiones adyacentes a un área edéntula [14].

Es una técnica predecible y versátil, la cual crea un ambiente vascular bilaminar que nutre el injerto, por lo cual el aporte sanguíneo está menos comprometido. Además, provee excelente estética debido al efecto genético que tiene el tejido conectivo sobre el epitelio que lo cubre, promueve aumento del grosor gingival (hecho de extrema importancia para prevenir la recidiva de la recesión del margen tisular) y proporciona un excelente control de la biopelícula, lo cual provee estabilidad y mantenimiento a la salud de los tejidos periodontales $[5,6,8,9,11,13]$.

Sin embargo, presenta algunas desventajas, ya que requiere de dos sitios quirúrgicos, puede presentarse sangrado, dolor posoperatorio o molestias en el sitio donador; es, además, un procedimiento técnicamente más sensible y algunas veces el paladar no posee suficiente tejido para servir como sitio donante $[5,6,8,9,11]$.

Al tomar en consideración sus ventajas e indicaciones, se reporta el presente caso con el objetivo de describir los resultados clínicos obtenidos tras realizar una técnica bilaminar usando un injerto de tejido conectivo subepitelial cubierto por un colgajo de espesor parcial desplazado coronalmente, en una recesión gingival clase II de Miller localizada en el 44, asociada a lesión cervical no cariosa y cantidad nula de encía adherida.

\section{Presentación del caso}

Paciente femenina, de 52 años de edad, con antecedentes de salud que acudió a consulta de periodoncia de la Clínica Estomatológica Docente "III Congreso del PCC (Partido Comunista de Cuba)" del municipio Matanzas. Afirmó estar preocupada por "cambio de posición de la encía en un diente". En la anamnesis refirió no presentar sangramiento gingival al cepillado, y como dato de interés señaló que se "mordía las uñas" con el 44 (14/44).

El examen clínico intrabucal contempló una valoración periodontal que se basó en la inspección de los tejidos gingivales, los cuales mostraban características normales en cuanto a color, consistencia, contorno, tamaño y textura. La posición se encontraba afectada solo en el 44 , ya que existía migración del margen gingival hacia apical con exposición radicular y abrasión en la zona cervical por vestibular. Los tejidos blandos interproximales ocupaban el nicho gingival y no presentaban alteraciones. Se midió el tamaño de la corona clínica del diente afectado con un Vernier marca Dentaurum desde su borde oclusal hasta el punto más apical del margen gingival, lo que arrojó un resultando de $12,3 \mathrm{~mm}$.

Con sonda periodontal de William se procedió a medir la profundidad del surco gingival por bucal del 44 (1 mm en la cara libre y de 0 en mesial y distal); su margen gingival ubicado a $5 \mathrm{~mm}$ apical del borde cervical de la abrasión vestibular sobrepasaba la unión mucogingival, al tomar también como referencia la línea amelocementaria (LAC) del 45. La recesión medía fue de $4 \mathrm{~mm}$ de ancho en sentido mesiodistal, y encía adherida de $0 \mathrm{~mm}$. La pérdida de inserción en la cara libre por vestibular del 44 era de aproximadamente $6 \mathrm{~mm}$ (al sumar la profundidad del surco gingival en la cara libre más el tamaño de la recesión por vestibular). En el sondaje no se detectaron signos de inflamación gingival (figura 1A, B, C).

El órgano dentario 44 estaba vital, libre de movilidad, caries y obturación, y presentaba buena alineación en la arcada dentaria. La paciente mostraba higiene bucal adecuada, lo que se constató al aplicar el índice de análisis de la higiene bucal de Love, igual al 5\%. Se indicó radiografía periapical en la zona del 44 , apreciándose discreto aumento del espacio periodontal de dicho diente por mesial y distal; no se observó pérdida ósea interproximal, ni presencia de áreas radiolúcidas laterales ni periapicales. Con base en las características clínico-radiográficas del órgano dentario a tratar se establecieron los diagnósticos de recesión gingival clase II de Miller localizada en el 44, lesión cervical no cariosa en dicho diente y ausencia de encía adherida a ese nivel.

Se decidió como tratamiento un injerto de tejido conectivo subepitelial cubierto por un colgajo de espesor parcial desplazado coronalmente. Se ofreció la información necesaria a fin de satisfacer las inquietudes que podría tener la paciente respecto a su situación periodontal y al plan de tratamiento propuesto, y se procedió a solicitar su autorización mediante formato escrito de consentimiento informado.

En el plan de tratamiento se cumplió estrictamente con la preparación inicial. En la motivación se insistió en la necesidad del abandono del hábito 


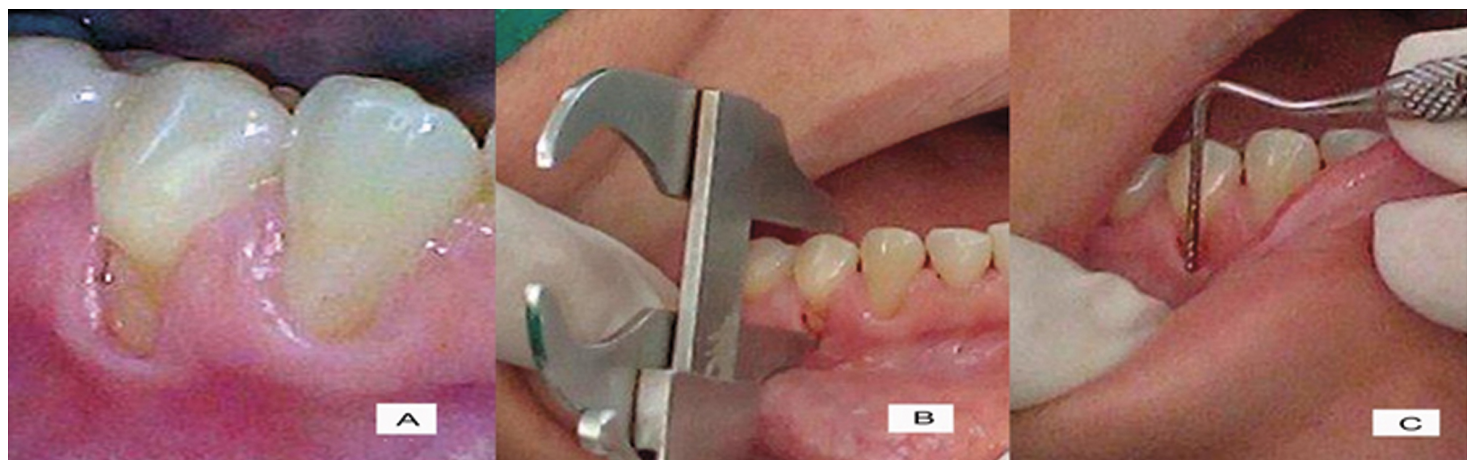

Figura 1. A. Recesión gingival clase in de Miller localizada en el 44, lesión cervical no cariosa y ausencia de encía adherida en dicho diente в. Medición de la corona clínica del 44. с. Sondaje del surco gingival del 44 Fuente: elaboración propia

(morderse las uñas con el 14 y el 44), así como en la enseñanza del cepillado correcto (técnica de Stillman modificado) con el uso de cepillo de cerdas blandas en la zona afectada.

\section{A. Procedimiento prequirúrgico}

Se prescribieron exámenes de laboratorio, tales como: estudio hemático completo, recuento plaquetario (PT y PTI) y glicemia. Los resultados arrojaron valores dentro del rango de normalidad.

\section{B. Acto quirúrgico}

Previa antisepsia del campo operatorio con solución acuosa de acetato de clorhexidina al 0,2\%, se anestesió el sitio quirúrgico con lidocaína al $2 \%$, epinefrina (1:80 000) y el uso de la técnica infliltrativa en ambos sitios (receptor y donante) en dos tiempos diferentes: primero se anestesió el sitio receptor en el fondo del surco vestibular de 43-45 al reforzar en la base de las papilas; luego, se colocó la anestesia en el sitio donante (zona palatina comprendida entre los órganos dentarios 26 y 27).

\section{Preparación de la superficie radicular}

Se raspó la superficie radicular expuesta del 44 con uñas de Moore y se alisó con curetas periodontales tipo Grace. No se usó acondicionador radicular.

\section{Preparación del lecho receptor}

Con hoja de bisturí \# 15 y mango de bisturí \# 3 marca Bard-Parker, se disecó un colgajo de espesor parcial con incisión festoneada que se extendió en sentido apical unos $5 \mathrm{~mm}$ más allá de la recesión del 44, y en sentido mesiodistal hasta la línea ángulo proximal de los dientes adyacentes al órgano dentario a tratar (de mesial del 43 a mesial del 45), introduciendo el bisturí entre la encía y la superficie radicular a nivel de la recesión gingival con mucho cuidado de no perforar la parte vestibular del lecho receptor. Con el bisturí orientado de forma perpendicular a la base de las papilas aledañas al 44, se realizó una incisión horizontal coronal a la LAC del segundo premolar inferior derecho y al borde cervical de la abrasión vestibular de dicho diente, de donde partió una descarga vertical mesial al 45 ligeramente divergente que se prolongó hasta más allá de la línea mucogingival (LMG). Se desinsertaron las fibras musculares, de modo que se dejó sin tensión el colgajo triangular diseñado que se extendió hasta mesial del 43 en forma de un bolsillo a través de una disección mucosa realizada con bisturí. Las papilas vecinas al 44 se desespitelizaron. Se estableció un lecho perióstico firme de 43 a 45 (figura 2A).

\section{E. Preparación del lecho donante}

En el paladar se seleccionó como sitio donador la zona comprendida entre el 2.6 y el 2.7, para lo cual se utilizó la técnica con dos incisiones horizontales: la primera incisión, aproximadamente a $2 \mathrm{~mm}$ desde el margen gingival hasta el hueso por encima del periostio; la segunda se realizó a $2 \mathrm{~mm}$ respecto a la primera y paralela a ella, por debajo del epitelio delimitando el tejido conectivo. A fin de liberar el injerto se realizó una incisión en su base y otras dos 
por mesial y distal. El tejido donante se removió con pinza de disección sin dientes y se colocó en una gasa estéril impregnada de suero fisiológico, de manera que quedó una estrecha zona del paladar que cicatrizaría por segunda intención. Se suturó la herida resultante con sutura continua (seda negra 4-0 no reabsorbible) y se colocó el adhesivo tisular Tisuacryl como apósito periodontal (figura 2B, C y D).

\section{Obtención del tejido conectivo y fijación del injerto en sitio receptor}

Se obtuvo un tejido conectivo de $12 \mathrm{~mm}$ de largo y $8 \mathrm{~mm}$ de alto con un delgado ribete epitelial, el cual se retiró con tijera fina y luego se retocó con el fin de ajustar su tamaño a 12 x $6 \mathrm{~mm}$ y el espesor a 1,6 mm, y así lograr una mejor adaptación y circulación inicial (figura 3A). El injerto se fijó al periostio del área receptora con puntos simples de sutura Catgut cromado 5-0 reabsorbible, lo cual garantizó su inmovilización durante las primeras horas y permite la ósmosis de nutrientes que mantuvieran al injerto hasta la formación de la circulación propia. El colgajo fue reposicionado coronalmente de manera tal que cubriera el tejido conectivo injertado, y fijara la parte más coronal mediante sutura suspensoria alrededor del cuello del diente. En la incisión vertical mesial al 45 se emplearon puntos simples y una sutura continua en el fondo del surco vestibular de 43 a 45, con el propósito de crear una nueva LMG. Se suturó con seda negra 4-0 no reabsorbible con aguja de $3 / 8$ de círculo con reverso cortante (figura 3B), y se colocó cemento quirúrgico Quirucém en el área intervenida.

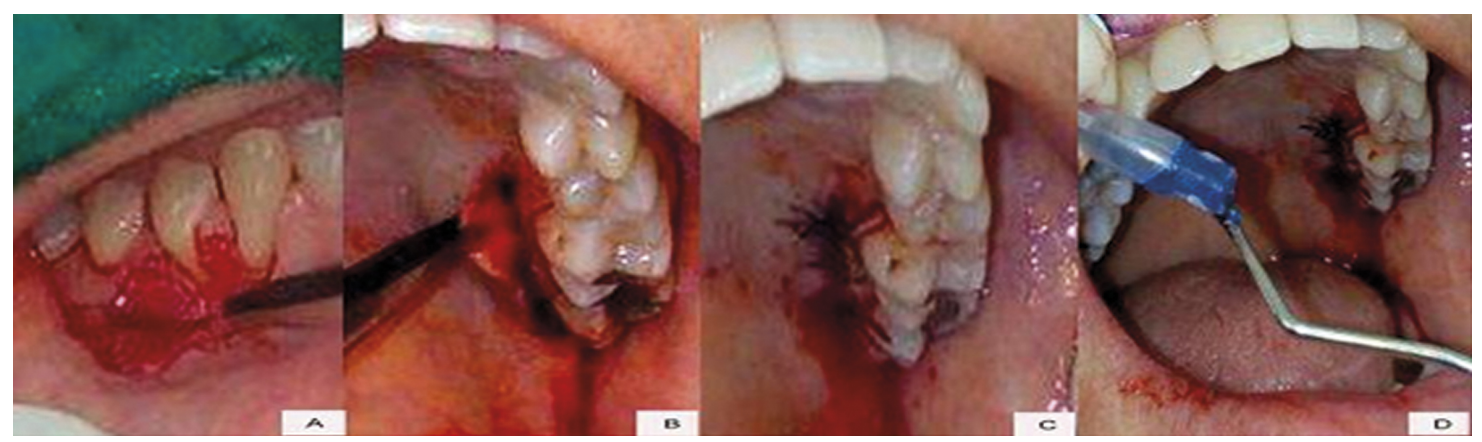

Figura 2. A. Preparación del lecho receptor de 43 a 45; в. Remoción del tejido donante de palatino de 26 a 27; c. Sutura del área donante; D. Aplicación de Tisuacryl como apósito periodontal en zona donante Fuente: elaboración propia

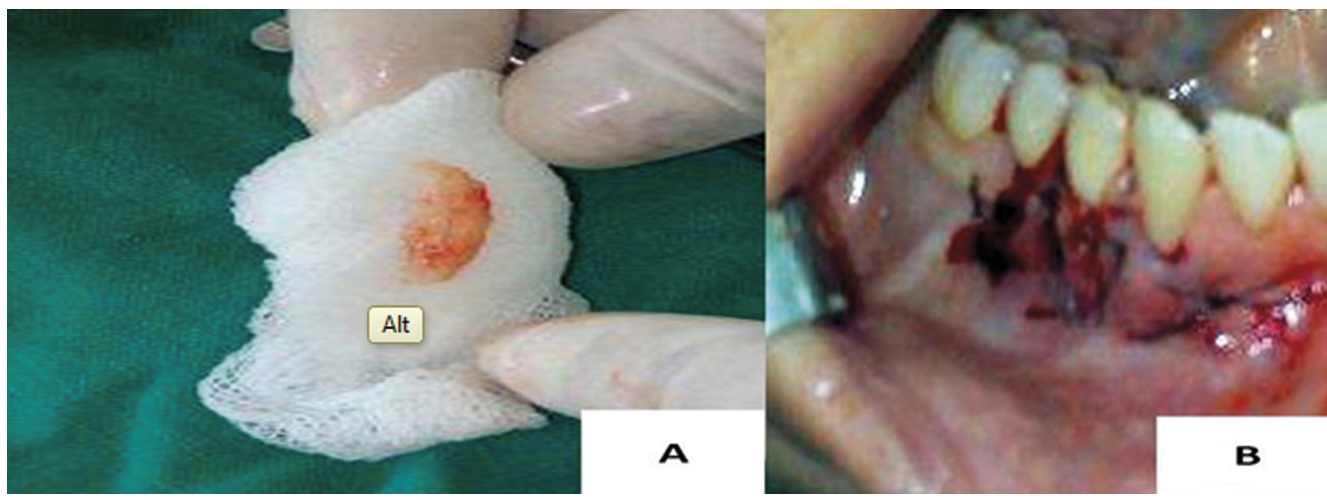

Figura 3. A. Tejido conectivo obtenido del paladar; в. Reposicionamiento del colgajo sobre el injerto de tejido conectivo previamente fijado al periostio y suturas de fijación en área receptora Fuente: elaboración propia 


\section{A. Posoperatorio}

Se prescribió analgésico oral y se recomendó ingerirlo solo en caso de dolor, Dipirona de $300 \mathrm{mg}$ (dos tabletas cada ocho horas), vitamina c, 1 tableta de $500 \mathrm{mg}$ cada 24 horas por 15 días, mantener la cabeza elevada y evitar acostarse en las primeras seis horas. Ingerir abundante líquido y alimentos blandos por dos semanas, realizar colutorios de solución acuosa de clorhexidina al $0,2 \%$ cada 12 horas a partir de las primeras 24 horas, por un periodo de siete días. Se orientó mantener cepillado dentogingival en las zonas no intervenidas. Ante cualquier alteración o malestar, se recomendó volver a la consulta. Se citó para evolución posoperatoria a la semana a fin de retirar sutura del paladar.

\section{B. Evolución posoperatoria}

A los siete días se retiró la sutura del paladar y se observó clínicamente adecuada cicatrización del área. La paciente no refirió dolor, ni molestias posoperatorias mediatas; relató haber ingerido el analgésico prescrito solo una vez después de la intervención quirúrgica (a las primeras dos horas posoperatorias). La zona injertada se mantenía protegida por el apósito periodontal. Se citó a la paciente de nuevo dentro de una semana para retirar cemento quirúrgico y sutura de la zona intervenida y realizar control evolutivo, y se indicó continuar con los colutorios de clorhexidina al $0,2 \%$ por siete días más.
A los 15 días del posoperatorio se retiró el cemento quirúrgico y las suturas del área intervenida; se observó clínicamente cobertura radicular completa, discretos signos de inflamación y escaso cúmulo de biopelícula. Se orientó cepillar el área de forma cuidadosa con cepillo de cerdas blandas y el empleo de la técnica de Stillman modificado, con énfasis en la importancia de la higiene bucal para mantener los resultados logrados con la técnica aplicada. Se indicó masajear la zona con el dedo pulgar por fuera de la cara (de apical a coronal) varias veces al día, a fin de favorecer la circulación sanguínea en el área, así como la integración y el remodelado del tejido injertado. Se suspendió el enjuague con clorhexidina (figura 4A).

Transcurrido un mes se observó clínicamente tejido gingival sin inflamación, recesión del 44 por completo cubierta, ganancia de tejido queratinizado y armonía de color entre la zona injertada y el área adyacente. El sitio donante mostraba adecuada cicatrización (figura 4B y C). Situación similar se encontró a los tres meses de evolución (figura 4D).

En el control realizado a los seis meses pudo constatarse una evolución clínica satisfactoria tanto en el área receptora como en el sitio donante.

Se encontró buen estado de salud periodontal y aspecto estético favorable en la zona receptora. Cobertura radicular completa determinada por la ubicación clínica del margen gingival a nivel del cuello del 44, al tomar como referencia la línea amelocementaria de los dientes vecinos. Corona clínica del 44 de 7,3 mm (figura 5A). Existió incremento en

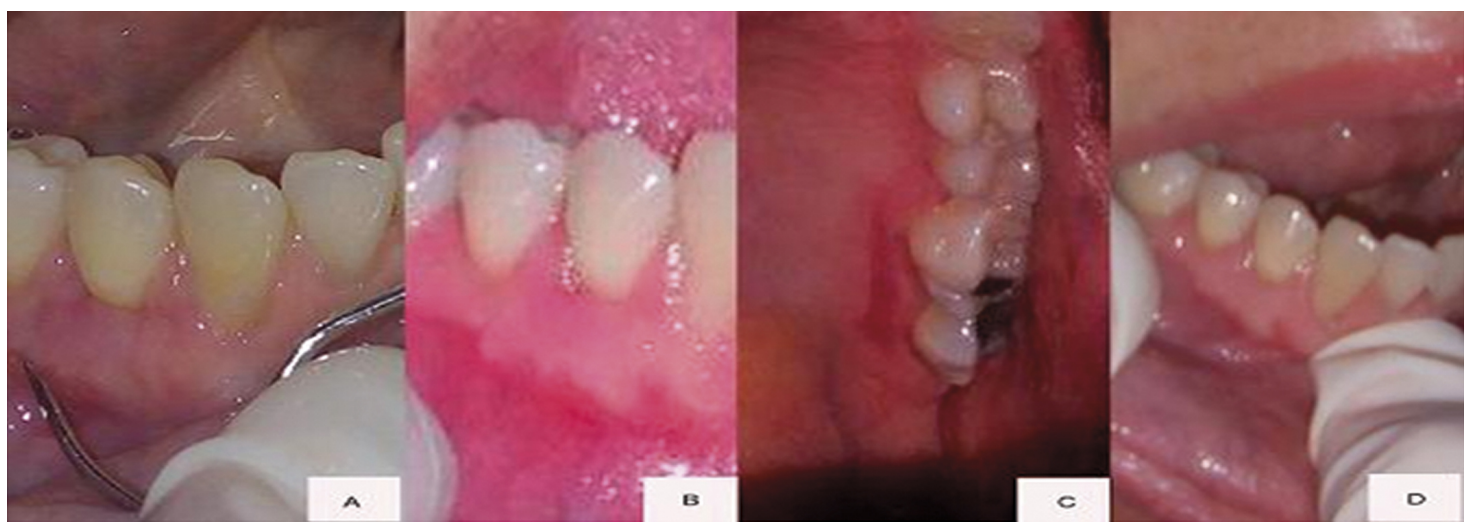

Figura 4. A. Evolución del área receptora a los 15 días de operada; в y c. Evolución del sitio receptor y el donante al mes.

D. Evolución del área receptora a los tres meses

Fuente: elaboración propia 
la altura de la encía queratinizada $(5 \mathrm{~mm})$, desde el punto más alto del margen gingival del 44 a la unión mucogingival, verificada con el uso de un Vernier (figura 5B); así como una adecuada inserción clínica de los tejidos gingivales a nivel del órgano dentario tratado: la sonda periodontal no penetró en el surco gingival de este, ni existió sangrado al sondaje (figura 5c). La zona donante ya no exhibía huellas de las incisiones realizadas para la toma del injerto (figura 5D).

\section{Discusión}

El aumento de encía adherida y el recubrimiento de superficies radiculares han sido objeto de innumerables esfuerzos y proyectos de investigación guiados al establecimiento y la selección de técnicas quirúrgicas y materiales que permitan lograr, de una manera predecible y no invasiva, el restablecimiento de tejidos periodontales compatibles con salud, función y estética periodontal [15].

Chambrone y Tatakis [16], en una revisión publicada en el 2015, plantean que si bien todos los procedimientos de cobertura radicular pueden lograr reducción significativa en la profundidad de la recesión y ganancia del nivel de inserción clínica para los defectos generados por recesiones gingivales clase I y in de Miller, los procederes quirúrgicos basados en injertos de tejido conectivo subepitelial proveen el mejor resultado en la práctica clínica porque logran un mayor porcentaje de cobertura radicular completa, así como incremento de tejido queratinizado. Aspectos similares se ofrecieron como conclusiones en [17] en el 2016.

También [18] reportan que los colgajos de tejido pediculado y los injertos libres de tejido blando logran buenos resultados en el mejoramiento de la recesión gingival, pues aumentan la inserción y la altura de la encía. Ellos aseveran que su éxito depende de la realización de un buen diagnóstico, de la localización de la recesión, de la técnica a emplear y del entrenamiento del especialista, y refieren que el injerto de tejido conectivo subepitelial cubierto por un colgajo avanzado coronalmente es el "gold estándard" de los tratamientos de cubrimiento radicular (en esto coinciden con [19]). En reportes publicados en el 2014, Goyal [20], así como Salhi [21], consideran también que esta técnica resulta factible para la cobertura de recesiones.

En el 2015, Vargas-Casillas et al. [22] presentaron un caso clínico en el que se evaluó si la agregación del derivado de la matriz del esmalte (DME) al procedimiento del colgajo de avance coronal con injerto de tejido conectivo subepitelial (CDC + ITCS) mejoraría la cantidad de cobertura radicular en recesiones gingivales clase I y II de Miller, comparados con el mismo procedimiento solo en un paciente con recesiones gingivales múltiples a los seis meses. Los resultados mostraron que en el periodo de evaluación señalado por los autores, ambos procedimientos (CAC + ITCSE + DME Y CAC + ITCSE) produjeron una significativa cobertura radicular; en promedio $2,83 \pm 1,16 \mathrm{~mm}(\mathrm{p}=0,001)$,

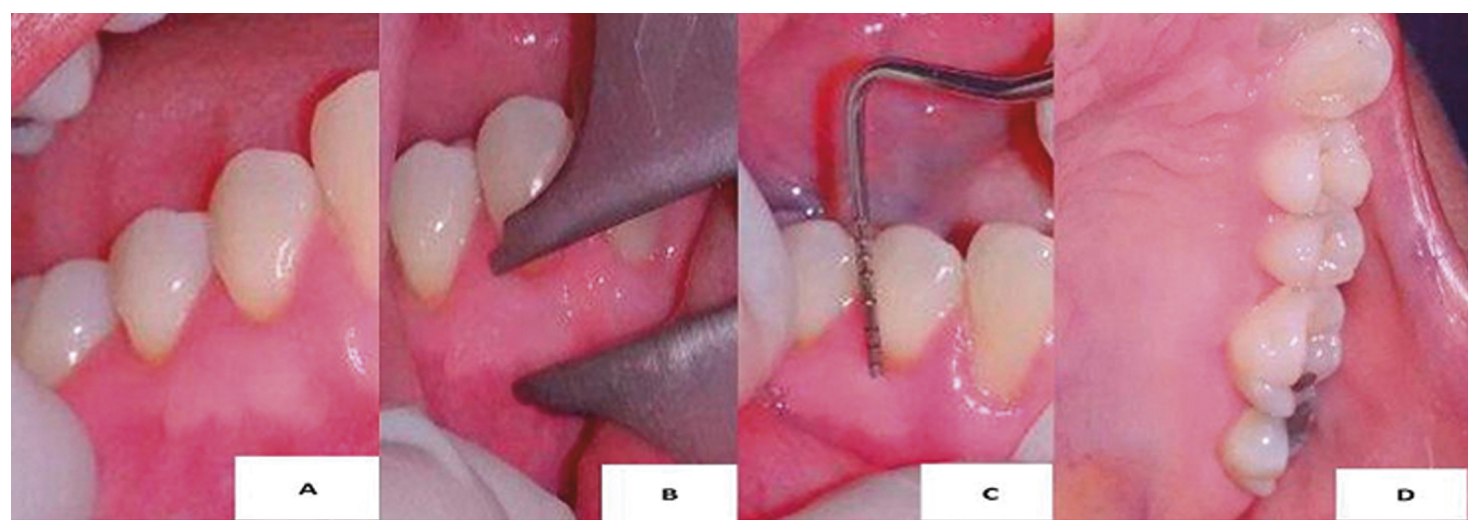

Figura 5. A y D. Evolución clínica del sitio receptor y donante a los seis meses de la intervención; в y c. Ganancia de encía queratinizada en la zona del 44 medida con un Vernier y sondaje del surco gingival del 44 Fuente: elaboración propia 
y $2,50 \pm 0,83 \mathrm{~mm}(\mathrm{p}=0,002)$, respectivamente. Llegaron a la conclusión de que la agregación del DME al procedimiento de CAC + ITCSE no mostró beneficio adicional.

Por su parte, García Rubio et al. [23] aseguran que el logro de recubrimiento radicular está determinado por el grado de afectación del hueso interproximal y es factible conocer de antemano las posibilidades de recubrimiento dependiendo de la clasificación de la recesión según Miller. Sin embargo, Henrique et al. [13] demostraron que, bajo una estrategia quirúrgica apropiada, se puede obtener cobertura radicular completa en las recesiones clase III.

Es importante señalar que, con frecuencia, las recesiones gingivales están asociadas a lesiones cervicales no cariosas. Estas tienen una estrecha relación no solo por compartir factores etiológicos, sino también porque, en muchas ocasiones, deben ser tratadas en conjunto a fin de lograr excelentes resultados funcionales y estéticos. La terapia con injertos de tejido conectivo subepitelial proporciona una alternativa biológica y definitiva puesto que, además de la mejoría estética, funciona como barrera de tejido en contra de posibles rompimientos futuros secundarios a la inflamación asociada a irritantes locales o abrasión traumática por cepillado dental [24].

Al tomar en consideración lo referido, se decidió reportar el presente caso clínico en el que se utilizó una técnica bilaminar, y en la cual el injerto de tejido conectivo (ITC) obtenido del paladar se colocó en el sitio receptor y se cubrió con un colgajo de espesor parcial desplazado coronalmente. La ausencia de tejido queratinizado apical a la recesión gingival clase II de Miller presente en esta paciente, así como la anchura del defecto, justifica el procedimiento quirúrgico empleado, ya que este se encuentra indicado en biotipos periodontales finos y en áreas de caninos y premolares, con el fin de aumentar el espesor del tejido marginal, evitar la contracción y favorecer la estabilidad de la cobertura radicular en el tiempo [25].

Con esta técnica también se pueden tratar defectos anchos y profundos, de manera que el ITC recibe una doble vascularización, se reduce el riesgo de necrosis del injerto y aumenta la predictibilidad de recubrimiento [25]. En conformidad con los reportes de de Kuis [26] en el 2013, con los de Vargas et al. en el 2015 [9] y con los de Sales et al. en el 2016 [5].
Por su parte, Zucchelli [27] et al. en el 2014 realizaron un ensayo clínico aleatorizado con el propósito de comparar la cobertura radicular a corto y largo plazo, así como los resultados estéticos de un colgajo de avance coronal (CAC) solo o en comparación con el colgajo de avance coronal combinado con injerto de tejido conectivo (CAC + TC). En este trabajo no se demostró diferencia estadísticamente significativa entre los dos grupos en términos de cobertura radicular completa (CRC) a los seis meses y un año; sin embargo, a los cinco años se observó una reducción estadísticamente mayor de la recesión y una mayor probabilidad de CRC, un mayor aumento de tejido queratinizado bucal y una mejor evaluación de contorno en el grupo tratado con CAC + TC. Los pacientes que recibieron CaC solo, al primer año y a los cinco años mostraron un mejor curso posoperatorio y una mejor combinación de color.

Quispe-López et al. [6] en su trabajo "Injerto de tejido conectivo en el tratamiento de recesiones gingivales. A propósito de dos casos", hacen alusión a opiniones referidas por Cortellini y Pini-Prato, quienes consideran que un colgajo de avance coronal solo - en muchos casos - consigue una cobertura completa de la raíz, se mantiene estable en el tiempo, es menos invasivo para el paciente, requiere menos tiempo de sillón y, es probable, menos habilidad quirúrgica. Existe la hipótesis de que esta técnica solo podría aplicarse con éxito cuando la encía residual es gruesa y ancha, por lo que en el caso presentado esta técnica no sería posible. Estos autores [6] plantean que, una vez el tejido gingival es más grueso, el uso del ITC parece innecesario, mientras que en los biotipos intermedios y finos el injerto es muy aconsejable.

Existen diferentes variantes de la técnica según el tipo de colgajo que cubrirá el tejido conectivo en el lecho receptor, y también según la técnica de obtención del injerto de la zona palatina donante.

El procedimiento quirúrgico que se utilizó en este caso fue similar al injerto de tejido conectivo subepitelial presentado por Langer y Langer ${ }^{[14]}$ en 1985, pero con algunas modificaciones. En lugar de dos incisiones verticales se realizó solo una descarga vertical mesial al 45 (colgajo triangular), se diseñó un sitio receptor más amplio que en la técnica de Langer y un colgajo de espesor parcial que se desplazó en sentido coronal que cubrió por completo el tejido conectivo injertado. 
En la zona donante también se efectuaron modificaciones a las técnicas descritas de forma convencional, ya que se tomó el injerto de la zona palatina de 26 a 27. Se tuvieron en cuenta consideraciones anatómicas de la paciente tales como un buen espesor de fibromucosa a ese nivel y un paladar profundo. Se podía visualizar la emergencia de los vasos en la porción laxa del paladar, lo que sirvió de guía para obtener el tejido conectivo sin lesionar ningún vaso sanguíneo. Es necesario comentar que la zona cruenta que permaneció expuesta luego de realizar la sutura continua en el área donante fue muy estrecha y quedó protegida por el adhesivo tisular (Tisuacryl), lo que le permitió a la paciente tener una aceptable evolución posoperatoria. Sin embargo, sería prudente - siempre que sea posible- usar la técnica de una incisión, a fin de lograr un cierre por primera intensión.

La técnica aplicada en el caso clínico reportado incrementó la altura de la encía queratinizada $(5 \mathrm{~mm})$ y logró cubrir la recesión gingival clase II de Miller localizada en el 44, la cual estaba asociada a una abrasión cervical vestibular. Estos parámetros se mantuvieron estables al mes, a los tres y a los seis meses. El contorno gingival mejoró de manera progresiva. A pesar de que en este trabajo solo se describe un caso clínico, los resultados logrados fueron similares a los reportados en [27] y por [22] a los seis meses, y por [28] al año.

El tejido que se utilizó para el injerto se acopló al defecto radicular y, al parecer, funcionó como soporte para evitar el colapso sobre el "espacio muerto" producido por la abrasión, de modo que proporcionó un cubrimiento radicular completo con una apariencia clínica favorable. Resultados estos similares a los relatados en el 2014 por GarzaLeija [29] en un estudio longitudinal realizado en su trabajo de tesis de maestría.

Si bien es cierto que varios autores $[5,6,8,9,11$, $13,17,27]$ consideran como una de las ventajas del injerto de tejido conectivo subepitelial cubierto por un colgajo avanzado coronalmente el aumento del tejido queratinizado, resulta interesante comentar algunas consideraciones que se reportan en la literatura con respecto a la importancia o no del ancho o el volumen de la encía adherida (EA) en la salud periodontal $[30,31]$.

Por ejemplo, Cartagena-Molina et al. [31], en el 2013, publicaron un artículo de revisión en el que hacen referencia a estudios realizados al respecto. Entre ellos se destacan el de Lang y Loe en 1972, quienes encontraron que $2 \mathrm{~mm}$ de ancho de encía queratinizada (EQ) (correspondiente a $1 \mathrm{~mm}$ de $\mathrm{EA}$ ) es "adecuado" para conservar la salud gingival, y afirman que en áreas con menos de $2 \mathrm{~mm}$ de EQ la inflamación era persistente, aun con una adecuada higiene oral. Asimismo, el de Miyasato et al. con respecto a gingivitis inducida, en el que no se evidenció ninguna diferencia en la evolución del proceso inflamatorio cuando fueron comparadas áreas con una mínima $(\leq 1 \mathrm{~mm})$ o apreciable $(\geq 2 \mathrm{~mm})$ cantidad de EQ. En ambos solo relacionaron hallazgos clínicos y no histológicos.

También estos autores [31] describen los resultados del examen histológico de tres estudios sobre modelos animales realizados en la Universidad de Gotemburgo con el objetivo de proporcionar una respuesta a la falta de evidencia biológica sobre la relación existente entre la cantidad EQ y la salud periodontal. Demostraron que no hubo diferencias en la extensión de la inflamación en el tejido conectivo subyacente cuando se tiene un área adecuada o inadecuada de EQ. Esto se validó luego con seguimientos clínicos de pacientes que fueron sometidos a procedimientos de aumento gingival, de manera que se concluyó que una banda estrecha de EA no es la única indicación para la realización de una cirugía periodontal.

Apuntan ellos a que en la en la actualidad, una cantidad "adecuada" de EA no se ha determinado, y su presencia en odontología restauradora y en ortodoncia puede ser importante hasta cierto punto [31]. La decisión sobre la necesidad de realizar un injerto de EA existirá en dependencia del juicio clínico de cada caso y la condición de higiene oral del paciente. El procedimiento podría estar indicado en áreas en las que la recesión gingival y la inflamación están presentes a pesar de las buenas medidas de higiene oral, y en las que la recesión progresa todavía después de un periodo de varios meses; en la planificación de restauraciones dentarias subgingivales que presenten áreas estrechas de encías adheridas; en dientes pilares utilizados para prótesis fijas o removibles, en los que el área de la encía adherida esté reducida; y en dientes con deficiencias mucogingivales que serán sometidos a tratamientos de ortodoncia, sobre todo cuando se planeen movimientos por fuera del hueso alveolar.

Así, entonces, se concluye que la técnica aplicada mostró resultados favorables respecto a cobertura radicular, aumento de la cantidad de encía queratinizada y buen aspecto estético. 
Se recomienda realizar el seguimiento a este caso, a fin de observar el comportamiento de la cobertura radicular, el nivel de inserción y la ganancia de encía queratinizada en el tiempo, así como realizar estudios longitudinales con este propósito en un mayor número de pacientes.

\section{Referencias}

[1] Guirnald EA, Caffesse RG. Localized gingival recessions: etiology and prevalence. The J of the Wes Soc Period. 25(1):3-9. PubMed PMID: 141652.

[2] Lindhe J. Periodontología Clínica. 3 ed. Buenos Aires: Editorial Panamericana; 2005.

[3] Rios FS, Costa RS, Moura MS, Jardim JJ, Maltz M, Haas AN. Estimaciones y evaluación de riesgo multivariable de la recesión gingival en la población de adultos de Porto Alegre, Brasil. J Clin Periodontol. 2014 nov;41(11):1098-107. doi: http://dx.doi. org/10.1111/jcpe.12303 .

[4] Bignozzi I, Crea A, Capri D, Littaru C, Lajolo C, Tatakis DN. Root caries: a periodontal perspective. J Periodontal Res. 2014;49(2):143-163. Disponible en: https://www.ncbi.nlm.nih.gov/pubmed/23647556

[5] Sales D, Rettori E, Romanelli H, Achinini G, Adam E. Tratamiento de múltiples recesiones gingivales con diferentes técnicas quirúrgicas: descripción de un caso clínico. Actas odontol. 2016 mar;7(1). Disponible en: https://revistas.ucu.edu.uy/index.php/ actasodontologicas/article/view/1075

[6] Quispe-López N, Garrido-Martínez P, Malpica-Morales $\mathrm{B}, \mathrm{G}^{\circ}$-Faria-García AG, Morales-Sánchez A. Injerto de tejido conectivo en el tratamiento de recesiones gingivales. A propósito de dos casos. Gac Den. Ca Clín. 2014 sept; Disponible en: http://docplayer. es/38531330-Injerto-de-tejido-conectivo-en-el-tratamiento-de-recesiones-gingivales.html

[7] Robles-Andrade MS. Predicción de la cobertura radicular completa: abordaje basado en evidencia. Rev Mex Periodontol. 2015;10-15. Disponible en: http:// www.medigraphic.com/pdfs/periodontologia/mp2015/mp151c.pdf

[8] Miller P D Jr. A classification of marginal tissue recession. Int J Periodont Rest Dent. 1985;5(2):8-13.

[9] Vargas MF, Menestrey L. Factores asociados al colgajo posicionado coronal de uno o dos dientes. Revisión de la literatura. Rev Fac Odontol Univ Antioq. 2015;26(2):368-397. Disponible en: http://www.scielo.org.co/scielo.php?pid=S0121-246X2015000100 009\&script=sci_arttext\&tlng=es
[10] Reino DM, Novaes A B, Maia L P, Palioto D B, Grisi-Márcio F M, Taba Jr Mário, et al. Treatment of gingival recessions in heavy smokers using two surgical techniques: a controlled clinical trial. Braz. Dent. J. 2012;23(1): 59-67. Disponible en: http:// www.scielo.br/scielo.php?script $=$ sci_arttext $\&$ pid=S010364402012000100011\&lng=en

[11] Gómes-Henriquez P S. Estética en periodoncia y cirugía plástica periodontal. Colombia: Editorial Panamericana Amolca; 2006.

[12] Tinajero-Aroni MA, Pimentel-Lopes de Oliveira GJ, Changoluisa G. Tinajero-Camacho FM. Coverage of Miller class I and II gingival recessions treated with subepithelial connective tissue graft, acellular dermal matrix, and enamel matrix proteins. Pilot study. Rev Odontol. unEsP mar/apr 2016;45(2) Disponible en: http://www.scielo.br/scielo.php?script=sci_arttext\&pid=S1807-25772016000200078\#f02

[13] Henriques PS, Pelegrine AA, Nogueira AA, Borghi MM. Application of subepithelial connective tissue graft with or without enamel matrix derivative for root coverage: a split-mouth randomized study. J Oral Sci. 2010 sep;52(3): 463-71.

[14] Langer B, Langer L. Subepithelial connective tissue graft technique for root coverage. J Periodontol. 1985;56(12):715-20.

[15] Durán-Yaneth J C, Alarcón C, Velásquez D. Aplicación de biomateriales de base biológica, moléculas bioactivas e ingeniería de tejidos en cirugía plástica periodontal. Una revisión. Rev. Clin. Periodoncia Implantol Rehabil Oral. 2012 dic;5(3):144-151. Disponible en: http://www.redalyc.org/articulo. oa?id=331028163009

[16] Chambrone L, Tatakis DN. Periodontal soft tissue root coverage procedures: a systematic review from the AAP Regeneration Workshop. J Periodontol. 2015; 86(2Suppl):S8-51. doi: http://dx.doi: 10.1902/ jop.2015.130674

[17] Bueno-Rossy LA. Cirugía Plástica Periodontal: reporte de un caso clínico. Odontoestomatología. 2016 may;18(27). Disponible en: http://www.scielo.edu. uy/scielo.php?script=sci_arttext\&pid=S1688-93392 016000100007

[18] López-Pinedo M, Li-Wong J. Cubrimiento radicular. Rev Estomatol Herediana. 2011;21(3):226-230. Disponible en: http://www.upch.edu.pe/vrinve/dugic/ revistas/index.php/REH/article/viewFile/171/143

[19] Bueno-Rossy L, Ferrari R, Shibli J. Tratamiento de recesiones y defectos mucogingivales mediante injertos de tejido conjuntivo en piezas dentarias e implantes. Rev. Odontoestomatol. 2015 nov;17(26). Disponible en: http://www.scielo.edu.uy/scielo.php?script=sci_arttext\&pid=S1688-93392015000200005 
[20] Goyal N, Grupta R, Pandit N, Dehiya P. Analysis of patient acceptance following treatment of Miller's class II gingival recession with acellular dermal matrix and connective tissue graft. J Indian Soc Periodontol. 2014 may-jun;18 (3):352-356. Disponible en: https://www.ncbi.nlm.nih.gov/pmc/articles/PM C4095629/

[21] Salhi L, Lecloux G, Seidel L, Rompen E, Lambert F. Coronally advanced flap versus the pouch technique combined with a connective tissue graft to treat Miller's class I gingival recession: a randomized controlled trial. J Clin Periodontol. 2014 apr;41(4):38795. Disponible en: http://dx.doi.org/10.1111/jcpe. 12207. PMID:24720640

[22] Vargas-Casillas AP, Mendoza-Espinosa BI, Borges-Yáñez SA. Comparación clínica del uso del colgajo de avance coronal e injerto de tejido conectivo subepitelial. Rev Odontol Mex;. 2015;19(4):263-272. Disponible en: http://www.medigraphic.com/facultadodontologiaunam

[23] García- Rubio A, Bujaldún-Daza A L, RodríguezArcilla A. Recesión gingival. Diagnóstico y tratamiento. Av Periodon Implantol 2015;27(1):19-24. Disponible en: http://scielo.isciii.es/scielo.php?script=sci_arttext\&pid=S1699-65852015000100003

[24] Mancini E., D’Atri E. Lesions cervicales no cariosas y recesiones gingivales, diagnóstico y tratamiento. Cír Od Santaf. 2013 abr;32:16-20. Disponible en: http://docplayer.es/search/?q=Mancini+E.+y+E.+D\%E2\%80\%99Atri\%2C+\%282013\%29+\%E2\%80\% 9CLesions+cervicales+no+cariosas $+\mathrm{y}+$ recesiones+ gingivales $\% 2 \mathrm{C}+\operatorname{diagn} \% \mathrm{C} 3 \% \mathrm{~B} 3$ stico $+\mathrm{y}+$ tratamiento $\% \mathrm{E} 2 \% 80 \% 9 \mathrm{D}+$

[25] Zucchelli G. Mucogingival esthetic surgery. Chicago, IL: Quintessence Pub. 2012; p. 514.

[26] Kuis D, Sciran I, Lajnert V, Snjaric D, Prpic J, Pezelj-Ribaric S, et al. Coronally advanced flap alone or with connective tissue graft in the treatment of single gingival recession defect: a longterm randomized clinical trial. J Periodontol. 2013 nov;84(11):1576-85. Disponible en: https://www. ncbi.nlm.nih.gov/pubmed/24382170
[27] Zuchelli G, Mounssif I, Mazzotti C, Stefanini M, Marzadori M, Petracci E, et al. Coronally advanced flap without connective tissue graft for the treatment of multiple gingival recessions: a comparative shortand long-term controlled randomized clinical trial. J Clin Periodontol. 2014 apr;41(4):396-403.

[28] Naveen-Vital-Kumar G, Raja-Vankatesh-Murthy K. A comparative evaluation of subepithelial connective tissue graft (SCTG) versus platelet concentrate graft (PCG) in the treatment of gingival recession using coronally advanced flap technique: A 12-month study. J Indian Soc Periodonto. 2013 nov-dec; 17(6):771-77. Disponible en: https://www.ncbi.nlm. nih.gov/pmc/articles/PMC3917209/

[29] Garza- Leija C. Tratamiento de la recesión gingival mediante el injerto de tejido conectivo subepitelial (técnica de Langer y Langer) en pacientes con abfracciones, estudio longitudinal [tesis]. Universidad Autónoma de Nuevo León, Facultad de Odontología. Maestría en Ciencias Odontológicas con Especialidad en Periodoncia. 2014. Disponible en: https:// www.google.com/search?q=T\%C3\%A9cnica+$\mathrm{de}+$ Zuchelli\&ie $=$ utf $-8 \&$ oe $=$ utf $-8 \& \mathrm{aq}=$ t $\&$ rls $=$ org . mozilla:es-ES:official\&client=firefox-a\&channel=sb

[30] Navarrete M, Godoy I, Melo P. Correlación entre biotipo gingival, ancho y grosor de encía adherida en zona estética del maxilar superior. Rev Clin Periodoncia Implantol Rehabil Oral. 2015. doi:_http:// dx.doi.org/10.1016/j.piro.2015.07.003

[31] Cartagena-Molina AF, Ruiz L M, dos Santos F A, Pilatti G L. ¿Qué es más importante en la salud periodontal, el ancho o el volumen de la encía adherida? Rev. ADM. 2013;70(5):233-238. Disponible en: http://www.medigraphic.com/cgi-bin/new/resumen.cgi?IDARTICULO $=46202$ 